\title{
Interleukin- 18 promoter genotype is associated with the risk of nasopharyngeal carcinoma in Taiwan
}

\author{
Chung-Yu Huang ${ }^{1,2}$ \\ Wen-Shin Chang ${ }^{3}$ \\ Chia-Wen Tsai ${ }^{3}$ \\ Te-Chun $\mathrm{Hsia}^{3}$ \\ Te-Chun Shen ${ }^{3, *}$ \\ Da-Tian $\mathrm{Bau}^{3-5, *}$ \\ Hao-Ai Shuil,*
}

'Graduate Institute of Medical Sciences, National Defense Medical

Center, Taipei, Taiwan; ${ }^{2}$ Taoyuan Armed

Forces General Hospital, Taoyuan,

Taiwan; ${ }^{3}$ Terry Fox Cancer Research

Laboratory, Translational Medicine

Research Center, China Medical

University Hospital, Taichung, Taiwan;

${ }^{4}$ Graduate Institute of Biomedical

Sciences, China Medical University,

Taichung, Taiwan; ${ }^{5}$ Department

of Bioinformatics and Medical

Engineering, Asia University, Taichung,

Taiwan

*These authors contributed equally to this work
This article was published in the following Dove Press journal:

Cancer Management and Research

Background: The incidence rate of nasopharyngeal carcinoma (NPC) has been documented to be high in Southeast Asia. Interleukin-18 (IL-18) is a multifunctional cytokine that augments interferon- $\gamma$ production and acts as an important immunomediator in the development of several types of cancer.

Patients and methods: This case-control study evaluated the role of $I L-18$ in NPC at the DNA level by genotyping its promoter polymorphisms at positions $-656,-607$, and -137 in a Taiwanese population. A total of 176 patients with NPC and age- and gender-matched 352 noncancer controls were included in this study.

Results: The CC genotype of the $I L-18-607$ polymorphism was found to be associated with significantly decreased risks of NPC compared to the AA genotype (crude OR $=0.50,95 \% \mathrm{CI}$ $=0.29-0.84, P=0.0093)$. This significant difference persisted even in the dominant and recessive models. A significantly lower $\mathrm{C}$ allele frequency at position -607 was detected in the NPC group (41.8\% vs 50.3\%; OR $=0.77 ; 95 \% \mathrm{CI}=0.63-1.04, P=0.0089$ ). Regarding $I L-18-656$ and -137 polymorphisms, there were no differential distributions of their genotypes between the NPC and control groups. After substratification of the subjects according to their smoking, alcohol consumption, and areca chewing status, the genotype distribution of the $I L-18-607$ polymorphism was found to be different only among nonsmokers between the NPC and control subgroups.

Conclusion: This study suggests that $I L-18$ plays an important role in the carcinogenesis of NPC in Taiwan and that the genotype-phenotype correlation of $I L-18-607$ polymorphism and its contribution to NPC need to be investigated further.

Keywords: genotype, $I L-18$, nasopharyngeal carcinoma (NPC), polymorphism, Taiwan

\section{Introduction}

Nasopharyngeal carcinoma (NPC) is a rapidly growing squamous cell carcinoma that is manifested by distant metastasis and affects both adults and children. ${ }^{1}$ It has been reported that infection caused by the Epstein-Barr virus is a major risk factor for NPC. ${ }^{2}$ Furthermore, studies have shown that cigarette smoking and alcohol consumption constitute the environmental risk factors for NPC. ${ }^{3,4}$ Mounting evidence indicates that the variant genotypes of the genes related to inflammatory cytokines could modulate the susceptibility of individuals to cancers. ${ }^{5-8}$ Polymorphisms of these genes may affect the cellular responses to inflammation and the secretion of cytokines by altering the expression and function of the genes. In NPC-endemic areas, although every individual is exposed to the same environment, only a few develop the disease, suggesting that genetic differences such as single-nucleotide polymorphisms (SNPs) contribute to the
Correspondence: Da-Tian Bau

Terry Fox Cancer Research Laboratory, Translational Medicine Research Center, China Medical University Hospital, 2 YuhDer Road, Taichung, 404, Taiwan Tel +886 422053366 (Ext 5805) Email datian@mail.cmuh.org.tw 
carcinogenesis of NPC. However, the molecular mechanism by which these factors induce NPC still remains unknown. Increasing knowledge of NPC at the genomic level could indicate the novel biomarkers for the early detection and prediction of not only NPC susceptibility but also prognosis.

Interleukin-18 (IL-18), initially known as interferon- $\gamma$ (IFN- $\gamma$ )-inducing factor, is a cytokine with a proinflammatory biofunction and produced by activated macrophages, epithelial cells, osteoblasts, keratinocytes, and also cancer cells..$^{9,10}$ Studies using animal models have demonstrated that administration of additional IL-18 resulted in the suppression of tumor growth, ${ }^{10,11}$ thus suggesting an important role of IL-18 in the host defense against cancer. Nevertheless, the role of IL-18 still remains incompletely understood. IL-18 is molecularly regulated and modulated under extremely complicated mechanisms in carcinogenesis, which is of great interest for oncologists. First, IL-18 may exert its tumor-suppressive effects by augmenting IFN- $\gamma$ production, particularly in the presence of IL-12, promoting Th1 differentiation, enhancing the cytotoxic activities of natural killer cells and CD8+ lymphocytes, ${ }^{10}$ inducing cancer cell apoptosis, ${ }^{12}$ and inhibiting angiogenesis. ${ }^{10}$ Second, the activities of IL-18 have been reported to be effected by the microenvironmental milieu status; for instance, IL-18 could enhance the differentiation of Th2 based on the presence of IL-4. Moreover, IL-18 has the ability to suppress the recognition of cancer cells by immune cells, thereby enhancing the ability of cancer cells to adhere to the walls of the vascular cells, inducing the production of angiogenic and growth factors, and promoting a prometastatic microenvironment. ${ }^{9,13,14}$ IL-18 levels were found to be much higher in the blood of patients with metastatic cancer than in patients without metastasis and in healthy people, thus deducing the reasonable hypothesis that serum IL-18 concentrations may be used as a noninvasive marker for detecting metastasis in breast cancer. ${ }^{15}$ All the abovementioned findings indicate that the pleiotropic cytokine IL-18 has the ability to biphasically perform its anticancerous and procancerous functions..$^{9,14}$

From the viewpoints of the genome, the expression of IL-18 appears to be regulated by at least two SNPs at the -607 (A/C) and -137 (G/C) positions of its promoter sequences. The former SNP may cause a change from $\mathrm{A}$ to $\mathrm{C}$ at position -607, which disrupts a potential cAMP-responsive elementbinding protein site, and the latter may cause a change at position -137 from $\mathrm{G}$ to $\mathrm{C}$, which may block the human histone $\mathrm{H} 4$ gene-specific transcription factor-1 nuclear factorbinding site. ${ }^{16}$ These differences in interaction between the sequences with related transcription factors are suggestive of the mechanisms through which the two promoter polymorphisms affect the overall $I L-18$ gene activity. Another well-known polymorphic site in the $I L-18$ promoter region is $-656(\mathrm{~A} / \mathrm{C})$ whose biofunction has not yet been clearly elucidated. In other words, the promoter polymorphism of $I L-18$ gene has been examined in autoimmune diseases ${ }^{16}$ but not frequently among cancers.

The majority of genomic studies published in the literature have focused on investigating the association between $I L-18-607$ and -137 polymorphisms and various types of cancers. Some of them have reported positive results, ${ }^{17-21}$ whereas others have reported negative findings. ${ }^{22,23}$ For instance, Pratesi et $\mathrm{al}^{24}$ showed that $I L-18-607$ or -137 polymorphism was not associated with NPC susceptibility. Similarly, Farhat et $\mathrm{al}^{25}$ also demonstrated a negative finding. However, Nong et $\mathrm{al}^{26}$ reported that the $-137 \mathrm{C} /-607 \mathrm{~A}$ haplotype of $I L-18$ was associated with a significantly increased risk of NPC compared with its counterpart, the $-137 \mathrm{G} /$ 607C haplotype. In 2013, a meta-analysis investigating the contribution of IL-18 genotypes to cancer risk proposed that the C-607A polymorphism is significantly associated with overall cancer risk, especially in NPC and gastrointestinal cancer, and the G-137C polymorphism is associated with an increased overall cancer risk in Asian populations and also significantly increases the risk of NPC. ${ }^{27}$ In the present study, the SNPs at -656 (A/C, rs1946519), -607(A/C, rs 1946518), and $-137(\mathrm{G} / \mathrm{C}$, rs 187238) in the promoter region of the $I L-18$ gene were identified and analyzed in patients with NPC in Taiwan.

\section{Patients and methods Study subjects}

During the period from 2003 to 2009 , a total of 176 patients with NPC were included through the general surgery outpatient clinics in China Medical University Hospital. All the patients were asked to participate in the project freely and voluntarily and to complete a questionnaire, in addition to providing $5 \mathrm{~mL}$ of their peripheral blood samples. The welldesigned questionnaire consisted of questions pertaining to basic characteristics and history of cancer. In addition, the frequency of alcohol consumption, areca chewing, and smoking behaviors were recorded, in which "ever" was defined as more than twice a week for at least 1 year and then reclassified during analysis. The histological status of NPC was identified and judged by expert surgeons according to the 1991 WHO classification system. The histologic types included keratinizing squamous cell carcinoma (WHO type I) in 5 $(2.8 \%)$ and non-keratinizing carcinoma (WHO type II) in 
$171(97.2 \%)$ cases. Furthermore, type II was categorized into non-keratinizing differentiated carcinoma (WHO type IIa) in $28(15.9 \%)$ and non-keratinizing undifferentiated carcinoma (WHO type IIb) in $143(81.3 \%$ ) cases.

For each patient with NPC, twice the number of age- and gender-matched cancer-free healthy subjects were selected from the pool of individuals undergoing regular health examination (age-matching was done within $<5$ years of the patient's first diagnosis) and included in the final comparison and evaluation. Consequently, a total of 352 healthy individuals, exactly twice the number of patients with NPC, were subjected to genotyping and final analysis. All the patients and healthy volunteers provided written informed consent. The study was approved by the authority from the institutional review board of China Medical University Hospital (DMR101-IRB1-306).

\section{DNA preparation}

Genomic DNA isolated from the peripheral blood leukocytes of each study subject was prepared using the QIAamp Blood Mini Kit (Qiagen NV, Venlo, the Netherlands), stored for long term at $-80^{\circ} \mathrm{C}$, diluted, and aliquoted for genotyping as a working stock at $-20^{\circ} \mathrm{C}$, as we do frequently. ${ }^{28,29}$

\section{IL-I 8 genotyping methodology}

The genotyping discrimination of $I L-18-607$ (A/C, rs1946518) and -137 (G/C, rs187238) polymorphisms was assessed using the ABI StepOne ${ }^{\text {TM }}$ Real-Time PCR System (Thermo Fisher Scientific, Waltham, MA, USA) and analyzed by the typical TaqMan assay. For genotyping the $I L-18-656$ (A/C, rs1946519) polymorphism, the PCRrestriction fragment length polymorphism technique was applied using the primers reported by Folwaczny et al. ${ }^{30}$ The forward primer 5'-AGGTCAGTCTTTGCTATCATTCCAGG-3' and the reverse primer 5'-CTGCAACAGAAAGTAAGCTTGCGGAGAGG-3' were used to amplify a 120-bp fragment of the $I L-18-656$ (A/C) polymorphism. The PCR products were cut by the restriction enzyme $M$ wo I, and the DNA fragments were resolved in 3.0\% agarose gel, stained by ethidium bromide, and visualized under UV $(260 \mathrm{~nm})$ light. For the A allele, a $120 \mathrm{bp}$ PCR fragment was observed, whereas for the C allele, two 96/24 bp fragments were observed. ${ }^{9}$

\section{Statistical analysis}

The genotypic and clinical data of all the 352 controls and the 176 patients with NPC were statistically analyzed. To ensure that the control subjects were representative of the Taiwan population and to prevent any possible genotyping errors, the deviation of the genotypic frequencies of the investigated SNPs in the control groups from those expected under the Hardy-Weinberg equilibrium was assessed using the goodness-of-fit test. In addition, Pearson's chi-squared test was used for assessing the statistical significance in the distribution of the investigated genotypes and Cochran-Armitage test was applied for the trend analysis. Student's $t$-test was used to examine the differences in age, which is a continuous index, between the two groups. The associations between NPC risk and $I L-18$ genotypes were determined statistically by calculating the ORs and the corresponding 95\% CIs using the logistic regression analysis, adjusted or unadjusted for these confounders. Any $P$-value $<0.05$ was considered to be statistically significant.

\section{Results}

\section{Comparisons of basic characteristics of NPC and control groups}

The frequency distributions of age, gender, and personal behavioral habits of the 176 patients with NPC and 352 noncancer control subjects are summarized in Table 1. Because we matched the patients with twice the number of controls, there was no significant difference in age and gender between the case and control groups $(P>0.05)$. There was also no significant difference between the case and control groups in terms of the distributions of personal behavioral habits, including smoking, alcohol consumption, and areca chewing status $(P>0.05)$ (Table 1).

\section{Association analysis of IL-I 8 genotypes and NPC risk in the study subjects}

The genotypes of -656 (A/C, rs1946519), -607(A/C, rs1946518), and -137 (G/C, rs187238) polymorphisms of $I L-18$ were determined in all the patients and the age- and gender-matched healthy controls, and the results are summarized in Table 2. The genotype frequencies of the -656 , -607 , and -137 polymorphisms of $I L-18$ in both the case and control groups fit the Hardy-Weinberg equilibrium.

The genotypes of the $I L-18$ promoter $-607(\mathrm{~A} / \mathrm{C})$ SNP were found to be differently distributed between patients and controls $\left(P_{\text {trend }}=0.0090\right)$ (Table 2, middle panel). In detail, the $I L-18-607(\mathrm{~A} / \mathrm{C})$ homozygous $\mathrm{CC}$ variant genotypes were associated with decreased risks of NPC (OR $=0.46,95 \% \mathrm{CI}$ $=0.25-0.78, P=0.0093$ ) (Table 2 , middle panel). In both the dominant and recessive models, there were significant associations with the risk of NPC (Table 2, middle panel). These 
Table I Demographic characteristics of the investigated NPC patients and noncancer healthy controls

\begin{tabular}{|c|c|c|c|c|c|c|c|}
\hline \multirow[t]{2}{*}{ Characteristics } & \multicolumn{3}{|c|}{ Controls $(n=352)$} & \multicolumn{3}{|c|}{ Cases $(n=176)$} & \multirow[t]{2}{*}{$P$-value ${ }^{a}$} \\
\hline & $\mathbf{n}$ & $\%$ & Mean (SD) & $\mathbf{n}$ & $\%$ & Mean (SD) & \\
\hline Age (years) & & & $48.7(10.8)$ & & & $49.3(9.4)$ & 0.7138 \\
\hline Gender & & & & & & & 1.0000 \\
\hline Male & 256 & 72.7 & & 128 & 72.7 & & \\
\hline Female & 96 & 27.3 & & 48 & 27.3 & & \\
\hline \multicolumn{8}{|l|}{ Behavioral habits } \\
\hline Cigarette smoker & 150 & 42.6 & & 73 & 41.4 & & 0.8519 \\
\hline Alcohol drinker & 124 & 35.2 & & 72 & 40.9 & & 0.2150 \\
\hline Areca chewer & 115 & 32.7 & & 54 & 30.7 & & 0.6926 \\
\hline \multicolumn{8}{|l|}{ Classification } \\
\hline KSCC (WHO type I) & & & & 5 & 2.8 & & \\
\hline NKC (WHO type II) & & & & $|7|$ & 97.2 & & \\
\hline NKDC (WHO type lla) & & & & 28 & 15.9 & & \\
\hline NKUC (WHO type Ilb) & & & & 143 & 81.3 & & \\
\hline
\end{tabular}

Note: 'Based on chi-squared test or Student's $t$-test.

Abbreviations: KSCC, keratinizing squamous cell carcinoma; NKC, non-keratinizing carcinoma; NKDC, non-keratinizing differentiated carcinoma; NKUC, non-keratinizing undifferentiated carcinoma; NPC, nasopharyngeal carcinoma.

significant results persisted even after adjusting for potential confounders, including age, gender, smoking, alcohol consumption, and areca chewing habits (Table 2, middle panel). Neither the genotypes nor the alleles at positions -656 and -137 showed any correlation with the risk of NPC in any of the groups (Table 2).

We also performed allelic analysis, and the results are shown in Table 3. Supporting the findings shown in Table 2, the results showed that the frequency of the variant allele $\mathrm{C}$ was $41.8 \%$ in the group of patients with NPC, which was significantly much lower than that (50.3\%) in the control group (adjusted $\mathrm{OR}=0.77,95 \% \mathrm{CI}=0.63-1.04, P=0.0089$ ). Again, the other two SNPs demonstrated no significant association with the risk of NPC (Table 3).

\section{Stratified analysis of $I L-I 8$ genotypes according to environmental factors}

We further performed stratified analyses of the genotypic association between the $I L-18-607$ polymorphism and the risk of NPC according to potential environmental risk factors in Taiwan, including cigarette smoking, alcohol consumption, and areca chewing habits. The adjusted ORs for carriers with the genotypes $\mathrm{AC}$ and $\mathrm{CC}$ at $I L-18-607$ were 0.69 and 0.37 among nonsmokers $(95 \% \mathrm{CI}=0.42-1.02$ and $0.22-0.73$, $P$-values 0.0947 and 0.0091 , respectively) and 0.81 and 0.62 among smokers $(95 \% \mathrm{CI}=0.41-1.42$ and $0.33-1.37, P$-values 0.6137 and 0.3385 , respectively). The protective effects of the IL-18-607 genotype against the risk of NPC appeared to be more obvious among nonsmokers (Table 4). At the same time, there was also no interaction between the $I L-18-656$ or -137 genotype and any of the environmental risk factors (data not shown).

\section{Discussion}

Unlike other head and neck cancers, NPC is characterized by its specific multifactorial etiology, worldwide geographical distribution, and extremely high sensitivity to radiotherapy and chemotherapy induction during therapeutic processes. ${ }^{31}$ For several years, the members of Terry Fox Cancer Research Laboratory have been working on genomic biomarkers for early detection and prediction in Taiwan, where NPC is prevalent and causes several cancer-related deaths. ${ }^{32-36}$ Cytokines play a complex role in the initiation and progression of inflammation and tumorigenesis. ${ }^{37}$ Studies have confirmed that the proinflammatory cytokine IL-18 possesses antitumor capacity against lung cancer in several murine models. ${ }^{14,38}$ In addition, preclinical trials used the recombinant human IL-18 as an antidote and found it to be beneficial for the examined patients. ${ }^{39}$ However, despite the conventional view that IL-18 is an anticancer agent, some reports have also suggested that this multifunctional cytokine exhibits a procancerous activity under some conditions. ${ }^{14}$ Recently, an increasing number of studies have shown that various genotypes of cytokine genes may influence the production and serum levels of cytokines, which may be closely associated with susceptibility to certain human diseases. ${ }^{16-21}$ Among the numerous SNPs, all the following three polymorphisms selected for this study are located in the promoter region of IL-18: -656 (G/T), -607 (C/A), and -137 (G/C). It has been reported that these polymorphisms cause differences in 
Table 2 Distribution of IL- $/ 8$ genotypes among the NPC patients and noncancer healthy controls

\begin{tabular}{|c|c|c|c|c|c|c|c|}
\hline & \multicolumn{2}{|c|}{ Controls } & \multicolumn{2}{|c|}{ Patients } & \multirow[t]{2}{*}{ OR $(95 \% \mathrm{Cl})$} & \multirow[t]{2}{*}{ OR $(95 \% \mathrm{CI})^{a}$} & \multirow[t]{2}{*}{$P$-value ${ }^{b}$} \\
\hline & $n$ & $\%$ & $n$ & $\%$ & & & \\
\hline \multicolumn{8}{|l|}{ IL-I 8-656 } \\
\hline AA & 134 & 38.0 & 64 & 36.4 & 1.00 (reference) & 1.00 (reference) & \\
\hline$A C$ & 150 & 42.6 & 80 & 45.4 & I.I2 (0.75-I.67) & $1.02(0.68-1.43)$ & 0.5913 \\
\hline $\mathrm{CC}$ & 68 & 19.3 & 32 & 18.2 & $0.99(0.59-1.65)$ & I.03 (0.62-I.7I) & 0.9550 \\
\hline $\begin{array}{l}P_{\text {trend }}{ }^{c} \\
\text { Carrier comparison }\end{array}$ & & & & & & & 0.9326 \\
\hline $\mathrm{AA}+\mathrm{AC}$ & 284 & 80.7 & 144 & 81.8 & I.00 (reference) & I.00 (reference) & \\
\hline $\mathrm{CC}$ & 68 & 19.3 & 32 & 18.2 & $0.93(0.58-1.48)$ & $0.98(0.62-1.30)$ & 0.7534 \\
\hline AA & 134 & 38.0 & 64 & 36.4 & I.00 (reference) & I.00 (reference) & \\
\hline $\mathrm{AC}+\mathrm{CC}$ & 218 & 62.0 & 112 & 63.6 & $1.07(0.74-1.57)$ & $1.03(0.83-1.39)$ & 0.7029 \\
\hline \multicolumn{8}{|l|}{ IL-I 8-607 } \\
\hline AA & 86 & 24.4 & 59 & 33.5 & 1.00 (reference) & 1.00 (reference) & \\
\hline$A C$ & 178 & 50.6 & 87 & 49.4 & $0.71(0.47-1.03)$ & $0.73(0.43-1.07)$ & 0.1121 \\
\hline $\mathrm{CC}$ & 88 & 25.0 & 30 & 17.1 & $0.50(0.29-0.84)$ & $0.46(0.25-0.78)$ & 0.0093 \\
\hline $\begin{array}{l}P_{\text {trend }}^{c} \\
\text { Carrier comparison }\end{array}$ & & & & & & & 0.0090 \\
\hline$A A+A C$ & 264 & 75.0 & 146 & 82.9 & I.00 (reference) & 1.00 (reference) & \\
\hline $\mathrm{CC}$ & 88 & 25.0 & 30 & 17.1 & $0.62(0.39-0.98)$ & $0.59(0.37-0.89)$ & 0.0386 \\
\hline $\mathrm{AA}$ & 86 & 24.4 & 59 & 33.5 & 1.00 (reference) & 1.00 (reference) & \\
\hline $\mathrm{AC}+\mathrm{CC}$ & 266 & 75.6 & 117 & 66.7 & $0.64(0.43-0.95)$ & $0.6 I(0.5 \mid-0.86)$ & 0.0274 \\
\hline \multicolumn{8}{|l|}{ IL-18-137 } \\
\hline GG & 281 & 79.8 & 133 & 75.6 & I.00 (reference) & 1.00 (reference) & \\
\hline GC & 65 & 18.5 & 38 & 21.6 & $1.24(0.79-1.94)$ & $1.17(0.7 I-2.14)$ & 0.3574 \\
\hline $\mathrm{CC}$ & 6 & 1.7 & 5 & 2.8 & I.76 (0.53-5.87) & $1.67(0.45-6.17)$ & 0.3515 \\
\hline$P_{\text {trend }}{ }^{c}$ & & & & & & & 0.2150 \\
\hline Carrier comparison & & & & & & & \\
\hline $\mathrm{GG}+\mathrm{GC}$ & 346 & 98.3 & 171 & 97.2 & 1.00 (reference) & 1.00 (reference) & \\
\hline $\mathrm{CC}$ & 6 & 1.7 & 5 & 2.8 & $1.69(0.5 \mathrm{I}-5.60)$ & I.47 (0.42-4.78) & 0.3888 \\
\hline GG & 281 & 79.8 & 133 & 75.6 & 1.00 (reference) & 1.00 (reference) & \\
\hline $\mathrm{GC}+\mathrm{CC}$ & 71 & 20.2 & 43 & 24.4 & $1.28(0.83-1.97)$ & $1.25(0.74-1.84)$ & 0.2619 \\
\hline
\end{tabular}

Notes: aAdjusted with age, gender, smoking, alcohol drinking, and areca chewing habits. 'Based on chi-squared test without Yates' correction. 'Cochran-Armitage test was applied for the trend analysis. Bold values are statistically significant.

Abbreviations: IL-18, interleukin-18; NPC, nasopharyngeal carcinoma.

Table 3 Allelic frequency analysis for IL-I 8 polymorphisms and NPC

\begin{tabular}{|c|c|c|c|c|}
\hline Allele & Controls, $\mathbf{n}(\%)$ & Patients, n (\%) & OR $(95 \% \mathrm{CI})^{\mathrm{a}}$ & $P$-value ${ }^{b}$ \\
\hline \multicolumn{5}{|l|}{ IL-I 8-656 } \\
\hline G & $418(59.4)$ & $208(59.1)$ & 1.00 (reference) & \\
\hline $\mathrm{T}$ & $286(40.6)$ & 144 (40.9) & $1.05(0.84-1.23)$ & 0.9294 \\
\hline \multicolumn{5}{|l|}{ IL-1 8-607 } \\
\hline A & $350(49.7)$ & $205(58.2)$ & 1.00 (reference) & \\
\hline C & $354(50.3)$ & $147(4 \mid .8)$ & $0.77(0.63-1.04)$ & $0.0089^{*}$ \\
\hline \multicolumn{5}{|l|}{ IL-18-137 } \\
\hline G & $627(89.1)$ & $304(86.4)$ & 1.00 (reference) & \\
\hline C & 77 (10.9) & $48(13.6)$ & $1.15(0.71-1.95)$ & 0.2006 \\
\hline
\end{tabular}

Notes: 'OR was adjusted with age, gender, smoking, alcohol drinking, and areca chewing. 'Based on chi-squared test without Yates' correction. Bold values are statistically significant.

Abbreviations: IL-18, interleukin-18; NPC, nasopharyngeal carcinoma.

their binding capacity with transcription factors. ${ }^{16}$ The two $I L-18$ promoter polymorphisms -607 and -137 were previously shown to be positively associated with several types of cancers, including esophageal squamous cell carcinoma ${ }^{17}$ and prostate cancer ${ }^{18}$ in Chinese subjects, colorectal cancer ${ }^{19}$ in Greek subjects, ovarian cancer ${ }^{20}$ in US subjects (Hawaiians), and breast cancer ${ }^{21}$ in Iranian subjects. In contrast, studies have also reported negative findings regarding the 
Table 4 OR for IL-I 8 promoter -607 genotype and NPC after stratified by smoking status

\begin{tabular}{|c|c|c|c|c|c|c|c|c|}
\hline \multirow[t]{2}{*}{ Genotypes } & \multicolumn{2}{|c|}{ Nonsmokers } & \multirow[t]{2}{*}{ OR $(95 \% \mathrm{CI})^{\mathrm{a}}$} & \multirow[t]{2}{*}{$P$-value ${ }^{b}$} & \multicolumn{2}{|l|}{ Smokers } & \multirow[t]{2}{*}{ OR $(95 \% \mathrm{Cl})^{a}$} & \multirow[t]{2}{*}{$P$-value ${ }^{\mathrm{b}}$} \\
\hline & Controls & Cases & & & Controls & Cases & & \\
\hline $\mathrm{AA}$ & 46 & 36 & 1.00 (reference) & & 40 & 23 & $\mathrm{I} .00$ (reference) & \\
\hline $\mathrm{AC}$ & 104 & 51 & $0.69(0.42-1.02)$ & 0.0947 & 74 & 36 & $0.8 \mathrm{I}(0.4 \mathrm{I}-\mathrm{I} .42)$ & 0.6137 \\
\hline $\mathrm{CC}$ & 52 & 16 & $0.37(0.22-0.73)$ & 0.009 I & 36 & 14 & $0.62(0.33-1.37)$ & 0.3385 \\
\hline$P_{\text {trend }}{ }^{c}$ & & & & 0.0080 & & & & 0.3399 \\
\hline
\end{tabular}

Notes: aORs were adjusted with age, gender, alcohol drinking, and areca chewing. 'Based on chi-squared test without Yates' correction. 'Cochran-Armitage test was applied for the trend analysis. Bold values are statistically significant.

Abbreviations: IL-18, interleukin-18; NPC; nasopharyngeal carcinoma.

association between $I L-18$ polymorphisms and squamous cell carcinoma of the head and neck cancers in Iranian subjects ${ }^{23}$ or oral cancer in Greek subjects. ${ }^{22}$ These discrepant results may be explained by the following three possibilities: the dual effects of IL-18 on the tumor immune response, ${ }^{14}$ the different types of tumors, and the various populations that were investigated. ${ }^{23}$

To our knowledge, this is the first study to investigate the SNPs at the positions $-656(\mathrm{G} / \mathrm{T}),-607$ (C/A), and $-137(\mathrm{G} / \mathrm{C})$ of the $I L-18$ promoter region in patients with NPC and noncancer healthy control individuals in a Taiwanese population and evaluate their contribution to the prediction of NPC risk. The results showed significant protective effects of the CC homo-variant genotypes and the $\mathrm{C}$ allele at position -607 of the $I L-18$ gene against NPC susceptibility (Tables 2 and 3 ). Regarding -656 and -137 genotypes of $I L-18$, there was no significant association between any genotype or allelic type and the risk of NPC (Tables 2 and 3). The positive finding indicating that the genotype of the $I L-18-607$ polymorphism was the determinant of NPC susceptibility and was found to be inconsistent with all the previous findings investigating the contribution of $I L-18$ genotypes to the risk of NPC, which were reported by Pratesi et al, ${ }^{24}$ Farhat et al, ${ }^{25}$ and Nong et al. ${ }^{26}$ In 2013, the meta-analysis reported by Guo and Xia ${ }^{40}$ combined all the available limited and updated literature and demonstrated that the $\mathrm{C}$ allele of $I L-18-607$ had a protective effect against the risk of NPC, especially for Asians, but not for Africans or Europeans. This is consistent with another meta-analysis reported in 2013. ${ }^{27}$ The first positive finding of this study, while uniquely consistent with the abovementioned overall meta-analysis, may be due to the fact that Taiwan is located in East Asia and is an island with conserved genetic, cultural, and environmental background. Although the sample size of this study is relatively larger than that of other studies, the contribution of $I L-18$ genotypes, especially those at $I L-18-607$, must be validated using larger samples and other populations across the world. All the results pertaining to the contribution of $I L-18$ genotypes to the risk of NPC are concisely summarized in Table 5. Among the NPC susceptibility genes investigated in this study, the roles of human leukocyte antigen (HLA) genes have been most intensively examined and claimed to be associated with the outcome of NPC by different research groups across the world. ${ }^{41-47}$ However, the findings are still inconclusive, ${ }^{48}$ and the detailed mechanisms underlying the effect have not been completely elucidated. Similar to the case of $H L A$ genes, further clinical studies investigating the contribution of $I L-18$ genotypes to NPC using larger sample sizes from various ethnic groups are still needed to fulfill the possibility of enhancing the early diagnosis and personalized treatment of NPC.

Substratification of the patients with NPC and noncancer subjects according to their personal behavioral habits revealed that the $I L-18-607$ genotype may play a significantly important role in the determination of the susceptibility to NPC among nonsmokers, but not smokers (Table 4). In 2017, Long et al reported that cigarette smoking was associated with an increased risk for NPC, especially for subjects who are young, male, and had early-onset, long-term, and undifferentiated type of NPC. ${ }^{4}$ However, the authors did not examine the effect of interaction between genotypes (such as $I L-18-607)$ and smoking on the risk of NPC. Therefore, further investigations are needed to elucidate the detailed mechanisms underlying the interaction between IL-18 and other molecules and environmental factors related to the etiology of NPC.

\section{Conclusion}

To our knowledge, this is the first study indicating a significant association between $I L-18-607$ polymorphism and the risk of NPC in Taiwan. This is also the first study to investigate the interaction between $I L-18$ genotypes and environmental factors in terms of the risk of NPC. The significant association between $I L-18-607$ polymorphism and the risk of NPC was particularly observed in patients without 


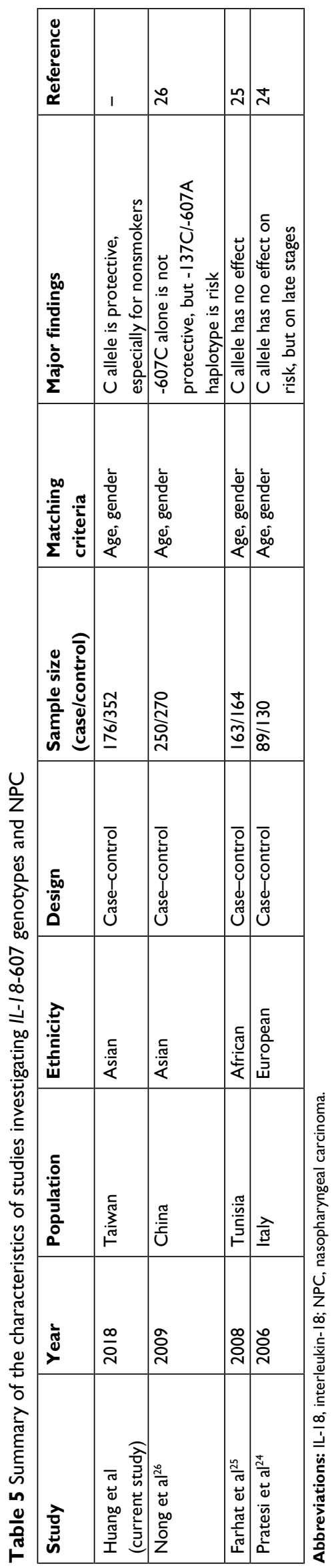

smoking behavior. Additional data from a larger number of subjects and other populations are required to validate the positive findings of $I L-18$ genotypes as a biomarker for early detection and prediction of NPC. These results suggest that $I L-18$ plays an important role in the carcinogenesis of NPC in Taiwan and that the interaction between $I L-18-607$ polymorphism and smoking in NPC etiology is worth further research.

\section{Acknowledgments}

The authors appreciate the otolaryngology colleagues and tissue-bank assistants for their outstanding technical assistance. We are also grateful to Cheng-Li Lin for the statistical consultation. The study was supported by Taiwan Ministry of Science and Technology grant to Bau (MOST106-2320-B-039-035), by Taoyuan Armed Forces General Hospital to Huang (ATTYGH-10628 and ATTYGH-10738) and publication fee from Taiwan Ministry of Health and Welfare Clinical Trial and Research Center of Excellence to the study group (MOHW107-TDU-B-212-123004).

\section{Disclosure}

The authors report no conflicts of interest in this work.

\section{References}

1. Lin CL, Lo WF, Lee TH, et al. Immunization with Epstein-Barr Virus (EBV) peptide-pulsed dendritic cells induces functional CD8+ T-cell immunity and may lead to tumor regression in patients with EBV-positive nasopharyngeal carcinoma. Cancer Res. 2002;62(23):6952-6958.

2. O'Neil JD, Owen TJ, Wood VH, et al. Epstein-Barr virus-encoded EBNA1 modulates the AP-1 transcription factor pathway in nasopharyngeal carcinoma cells and enhances angiogenesis in vitro. J Gen Virol. 2008;89(Pt 11):2833-2842.

3. Cheng YJ, Hildesheim A, Hsu MM, et al. Cigarette smoking, alcohol consumption and risk of nasopharyngeal carcinoma in Taiwan. Cancer Causes Control. 1999;10(3):201-207.

4. Long M, Fu Z, Li P, Nie Z. Cigarette smoking and the risk of nasopharyngeal carcinoma: a meta-analysis of epidemiological studies. $B M J$ Open. 2017;7(10):e016582.

5. Chang WS, Wang SC, Chuang CL, et al. Contribution of interleukin-4 genotypes to lung cancer risk in Taiwan. Anticancer Res. 2015;35(11):6297-6301.

6. Lo WJ, Chang WS, Hsu HF, et al. Significant association of interleukin-10 polymorphisms with childhood leukemia susceptibility in Taiwan. In Vivo. 2016;30(3):265-269.

7. Chang WS, Liao CH, Tsai CW, et al. The role of IL-10 promoter polymorphisms in renal cell carcinoma. Anticancer Res. 2016;36(5):2205-2209.

8. Shen TC, Tsai CW, Chang WS, et al. Association of Interleukin12A rs568408 with Susceptibility to Asthma in Taiwan. Sci Rep. 2017;7(1):3199.

9. Farjadfar A, Mojtahedi Z, Ghayumi MA, et al. Interleukin-18 promoter polymorphism is associated with lung cancer: a case-control study. Acta Oncol. 2009;48(7):971-976.

10. Nakanishi K, Yoshimoto T, Tsutsui H, Okamura H. Interleukin-18 is a unique cytokine that stimulates both $\mathrm{Th} 1$ and $\mathrm{Th} 2$ responses depending on its cytokine milieu. Cytokine Growth Factor Rev. 2001;12(1):53-72.

11. Gołab J. Interleukin 18--interferon gamma inducing factor--a novel player in tumour immunotherapy? Cytokine. 2000;12(4):332-338. 
12. Okano F, Yamada K. Canine interleukin-18 induces apoptosis and enhances Fas ligand mRNA expression in a canine carcinoma cell line. Anticancer Res. 2000;20(5B):3411-3415.

13. Park CC, Morel JC, Amin MA, et al. Evidence of IL-18 as a novel angiogenic mediator. J Immunol. 2001;167(3):1644-1653.

14. Vidal-Vanaclocha F, Mendoza L, Telleria N, et al. Clinical and experimental approaches to the pathophysiology of interleukin-18 in cancer progression. Cancer Metastasis Rev. 2006;25(3):417-434.

15. Günel N, Coşkun U, Sancak B, Günel U, Hasdemir O, Bozkurt S. Clinical importance of serum interleukin-18 and nitric oxide activities in breast carcinoma patients. Cancer. 2002;95(3):663-667.

16. Giedraitis V, He B, Huang WX, Hillert J. Cloning and mutation analysis of the human IL-18 promoter: a possible role of polymorphisms in expression regulation. J Neuroimmunol. 2001;112(1-2):146-152.

17. Wei YS, Lan Y, Liu YG, et al. Interleukin-18 gene promoter polymorphisms and the risk of esophageal squamous cell carcinoma. Acta Oncol. 2007;46(8):1090-1096.

18. Liu Y, Lin N, Huang L, Xu Q, Pang G. Genetic polymorphisms of the interleukin-18 gene and risk of prostate cancer. DNA Cell Biol. 2007;26(8):613-618.

19. Nikiteas N, Yannopoulos A, Chatzitheofylaktou A, Tsigris C. Heterozygosity for interleukin-18 -607 A/C polymorphism is associated with risk for colorectal cancer. Anticancer Res. 2007;27(6B):3849-3853.

20. Bushley AW, Ferrell R, Mcduffie K, et al. Polymorphisms of interleukin (IL)-1alpha, IL-1beta, IL-6, IL-10, and IL-18 and the risk of ovarian cancer. Gynecol Oncol. 2004;95(3):672-679.

21. Khalili-Azad T, Razmkhah M, Ghiam AF, et al. Association of interleukin-18 gene promoter polymorphisms with breast cancer. Neoplasma. 2009;56(1):22-25.

22. Vairaktaris E, Serefoglou ZC, Yapijakis C, et al. The interleukin-18 $-607 \mathrm{~A} / \mathrm{C}$ polymorphism is not associated with risk for oral cancer. Anticancer Res. 2007;27(6B):4011-4014.

23. Asefi V, Mojtahedi Z, Khademi B, Naeimi S, Ghaderi A. Head and neck squamous cell carcinoma is not associated with interleukin-18 promoter gene polymorphisms: a case-control study. J Laryngol Otol. 2009;123(4):444-448.

24. Pratesi C, Bortolin MT, Bidoli E, et al. Interleukin-10 and interleukin-18 promoter polymorphisms in an Italian cohort of patients with undifferentiated carcinoma of nasopharyngeal type. Cancer Immunol Immunother. 2006;55(1):23-30.

25. Farhat K, Hassen E, Bouzgarrou N, et al. Functional IL-18 promoter gene polymorphisms in Tunisian nasopharyngeal carcinoma patients. Cytokine. 2008;43(2):132-137.

26. Nong LG, Luo B, Zhang L, Nong HB. Interleukin-18 gene promoter polymorphism and the risk of nasopharyngeal carcinoma in a Chinese population. DNA Cell Biol. 2009;28(10):507-513.

27. Yang X, Qiu MT, Hu JW, et al. Association of interleukin-18 gene promoter $-607 \mathrm{C}>\mathrm{A}$ and $-137 \mathrm{G}>\mathrm{C}$ polymorphisms with cancer risk: a meta-analysis of 26 studies. PLoS One. 2013;8(9):e73671.

28. Yueh TC, Wu CN, Hung YW, et al. The Contribution of $M M P-7$ Genotypes to Colorectal Cancer Susceptibility in Taiwan. Cancer Genomics Proteomics. 2018;15(3):207-212.

29. Shen TC, Chang WS, Tsai CW, et al. The contribution of matrix metalloproteinase-1 promoter genotypes in Taiwan lung cancer risk. Anticancer Res. 2018;38(1):253-257.

30. Folwaczny M, Glas J, Török HP, et al. Polymorphisms of the interleukin-18 gene in periodontitis patients. J Clin Periodontol. 2005;32(5):530-534.
31. Chan AT, Teo PM, Johnson PJ. Nasopharyngeal carcinoma. Ann Oncol. 2002;13(7):1007-1015.

32. Tsou YA, Tsai CW, Tsai MH, et al. Association of caveolin-1 genotypes with nasopharyngeal carcinoma susceptibility in Taiwan. Anticancer Res. 2011;31(10):3629-3632.

33. Tsai CW, Tsai MH, Shih LC, et al. Association of interleukin-10 (IL10) promoter genotypes with nasopharyngeal carcinoma risk in Taiwan. Anticancer Res. 2013;33(8):3391-3396.

34. Liu JC, Tsai CW, Hsu CM, et al. Contribution of double strand break repair gene $\mathrm{XRCC} 3$ genotypes to nasopharyngeal carcinoma risk in Taiwan. Chin J Physiol. 2015;58(1):64-71.

35. Huang CY, Tsai CW, Hsu CM, et al. The role of XRCC6/Ku70 in nasopharyngeal carcinoma. Int J Oral Maxillofac Surg. 2015;44(12): 1480-1485.

36. Tsai CW, Chang WS, Gong CL, et al. Contribution of matrix metallopeptidase-1 genotypes, smoking, alcohol drinking and areca chewing to nasopharyngeal carcinoma susceptibility. Anticancer Res. 2016;36(7):3335-3340.

37. Aggarwal BB, Shishodia S, Sandur SK, Pandey MK, Sethi G. Inflammation and cancer: how hot is the link? Biochem Pharmacol. 2006;72(11):1605-1621.

38. Lian H, Jin N, Li X, et al. Induction of an effective anti-tumor immune response and tumor regression by combined administration of IL-18 and Apoptin. Cancer Immunol Immunother. 2007;56(2):181-192.

39. Herzyk DJ, Bugelski PJ, Hart TK, Wier PJ. Preclinical safety of recombinant human interleukin-18. Toxicol Pathol. 2003;31(5):554-561.

40. Guo XG, Xia Y. The Interleukin-18 promoter $-607 \mathrm{C}>\mathrm{A}$ polymorphism contributes to nasopharyngeal carcinoma risk: evidence from a meta-analysis including 1,886 subjects. Asian Pac J Cancer Prev. 2013;14(12):7577-7581.

41. Makni H, Daoud J, Ben Salah H, et al. HLA association with nasopharyngeal carcinoma in southern Tunisia. Mol Biol Rep. 2010;37(5):2533-2539.

42. Karanikiotis C, Daniilidis M, Karyotis N, et al. HLA Class II alleles and the presence of circulating Epstein-Barr virus DNA in Greek patients with nasopharyngeal carcinoma. Strahlenther Onkol. 2008;184(6):325-331.

43. Zeng XH, Xiao LL, Li J, Lu JX, Wang XN. Correlation of the polymorphism of HLA-A, B and DRB1 alleles with nasopharyngeal carcinoma in the south of China. Xi Bao Yu Fen Zi Mian Yi Xue Za Zhi. 2007;23(9):819-820.

44. Hildesheim A, Apple RJ, Chen CJ, et al. Association of HLA class I and II alleles and extended haplotypes with nasopharyngeal carcinoma in Taiwan. J Natl Cancer Inst. 2002;94(23):1780-1789.

45. Mokni-Baizig N, Ayed K, Ayed FB, et al. Association between HLA$\mathrm{A} /$-B antigens and -DRB1 alleles and nasopharyngeal carcinoma in Tunisia. Oncology. 2001;61(1):55-58.

46. Wang $\mathrm{R}, \mathrm{Hu} \mathrm{Y}$, Yindom LM, et al. Association analysis between HLA-A, -B, -C, -DRB1, and -DQB1 with nasopharyngeal carcinoma among a Han population in Northwestern China. Hum Immunol. 2014;75(3):197-202.

47. Burt RD, Vaughan TL, Mcknight B, et al. Associations between human leukocyte antigen type and nasopharyngeal carcinoma in Caucasians in the United States. Cancer Epidemiol Biomarkers Prev. 1996;5(11):879-887.

48. Yang H, Yu K, Zhang R, et al. The HLA-DRB1 allele polymorphisms and nasopharyngeal carcinoma. Tumour Biol. 2016;37(6):7119-7128. 
Cancer Management and Research

\section{Publish your work in this journal}

Cancer Management and Research is an international, peer-reviewed open access journal focusing on cancer research and the optimal use of preventative and integrated treatment interventions to achieve improved outcomes, enhanced survival and quality of life for the cancer patient.

The manuscript management system is completely online and includes

Submit your manuscript here: https://www.dovepress.com/cancer-management-and-research-journal

a very quick and fair peer-review system, which is all easy to use. Visit $\mathrm{http}: / / \mathrm{www}$.dovepress.com/testimonials.php to read real quotes from published authors. 